\title{
Interpretação fonológica e realização fonética durante o aprendizado de uma LE
}

\author{
Nina A. Lyubimova' \\ Professora Visitante CNPq/Instituto de Letras, UFRGS \\ Tradução de Tanira Castro²
}

\section{Abstract}

In the process of learning a foreign language, the individual must master a new phonetic discourse formation and its respective reception in that language, according to the "rules" of the intermediary system of paradigmatic units which are not similar to phonemes either of the first or the second system. These special units have a mixed character that differentiates them from a free variation. They can be called diaphonemes, if we understand that these units, which have a double character, become manifest in relation to the intermediary linguistic system and show themselves to be paradigmatic units. Nevertheless, in relation to the system of language that is studied, they show themselves to be syntagmatic units, and their variations are the realizations of the phonemes of the idiom in question. 


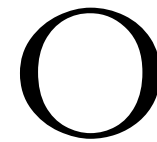

discurso sonoro representa o elo principal da comunicação acústica do indivíduo e, por isso, é reconhecido como um dos principais componentes da atividade comunicativa de conhecimento. Nesse sentido, os sons do discurso representam o principal objeto do ensino e da aprendizagem da LE. Para este artigo, temos em mente que não apenas o som completo representado por um determinado "conjunto" de movimentos dos órgãos articulatórios da fala, mas também o fato de que ele é o portador de uma determinada informação acústica, que pode ser representada pelo tom, timbre, intensidade, duração -, mas também o significado absoluto desse som, assim como as unidades segmentais sejam secundários, mas as suas variações de seus significados relativos representam precisamente a essência da fonética, como, por exemplo, a tonicidade e a entonação. Naturalmente, as informações gramaticais e semânticas também não podem ser atualizadas se esquecermos os sons do discurso.

O domínio do discurso em uma LE necessariamente pressupõe a formação de novas informações automatizadas que garantam a percepção e a realização das unidades de diferentes níveis dos componentes fonológicos de uma determinada LE, de acordo com o seu sistema e normas. A formação de novas operações ocorre sob as condições da ação da interferência interlingual, isto é, em condições de uma mútua interação de dois, e, às vezes mais, sistemas fonéticos (num sentido amplo) na consciência do indivíduo. Em conseqüência à ação da interferência, de uma forma específica, manifesta-se uma contradição entre os critérios universais e específicos, entre as semelhanças e diferenças existentes no primeiro ou no segundo sistemas lingüísticos e, por isso, o resultado dessa ação pode ser tanto 
positivo quanto negativo. De acordo com a interferência interlingual, possuímos também a interferência das operações auditivas motoras discursivas, formadas durante o processo de aprendizagem da LE e operações formadas durante o domínio de uma nova linguagem. A ação de mútua interação desta ou daquela interferência significativamente age durante o aprendizado do aspecto fonético do discurso da língua que se estuda.

Como sabemos, o indivíduo percebe o discurso na língua que estuda através do prisma de suas associações auditivas, que se baseiam nas línguas antes estudadas. Entretanto, observamos que a resposta à questão de qual das línguas que antes foi aprendida apresenta maior grau de interferência manifesta na aprendizagem da nova língua, permanece até agora uma questão que deixa muitas dúvidas para discussão.

No discurso em sua língua materna, o indivíduo é capaz de identificar os diferentes sons físicos como uma única unidade lingüística, porque as suas operações auditivas já estão automatizadas e obedecem às relações fonológicas de tal língua. Por outro lado, como sabemos, o indivíduo é capaz de diferenciar um maior número de sons do que a qualidade dos fonemas em sua língua materna (BONDARKO, 1981) e como eles se manifestam, o que representa a razão da identificação incorreta das características fonêmicas e dos fonemas em sua totalidade, durante a percepção dos sons da outra língua. Durante o domínio incompleto (pequeno) da língua estudada, o indivíduo percebe as diferenças fonêmicas, baseando-se em associações incorretas, em virtude das semelhanças físicas de seus correlatos "próprios" e "alheios" das características fonêmicas. Isso provoca, conseqüentemente, que em um mesmo nível fonético, também aquele mesmo critério diferencial possui diferentes características objetivas (ZINDER, 1979).

Se considerarmos não a etapa inicial de domínio de uma língua, mas o bilingüismo subordinado em diferentes situações de comunicação, então deveremos reconhecer que a ação da interferência fonética, durante a percepção do discurso na LE, normalmente 
permanece fechado para os interlocutores. O fato de que, mesmo num determinado nível de domínio da LE, o indivíduo cometa erros fonéticos, não impede a correta percepção do conteúdo significativo do discurso do interlocutor nativo de uma determinada língua, ainda não significa que, decodificando o sinal sonoro ele utiliza o sistema de critérios lingüísticos de tal LE. A ação negativa na interferência fonética em um determinado grau conhecido neutraliza o comportamento e a orientação significativa do discurso do ouvinte e diferentes tipos de informações supérfluas nele contidas. Além disso, durante o bilingüismo subordinado, o indivíduo em algum determinado grau já tem formado o seu sentido de adivinhação lingüística na outra língua, isto é, com maior ou menor sucesso, atua um mecanismo de prognóstico possível, permitindo um reconhecimento correto por parte do ouvinte. Ao contrário, palavras isoladas que contenham dificuldades fonéticas para portadores de outras LE, como de regra, pode perceber e identificar corretamente. Para identificar a ação da interferência, às vezes, é bastante difícil porque o indivíduo pode não prestar atenção nos erros do seu próprio discurso, mas fixar erros análogos no discurso de outras pessoas, que também não dominam completamente o aspecto sonoro do discurso da "outra" língua. Isso testemunha o fato de que o mecanismo auditivo de relação inversa ainda não está completo na LE, apesar de determinados padrões já existirem, o que permite a percepção dos erros no discurso do interlocutor. É possível também a seguinte situação: quando o indivíduo conhece e identifica os seus erros de pronúncia, consegue ouvi-los, mas não se encontra em condições de se autocorrigir porque a formação e a automatização das operações discursivas motoras na LE significativamente atrasaramse em relação à formação e à automatização das operações auditivas. Observamos que situações semelhantes também se manifestam na LM, não somente na LE (BERNSHTEIN, 1930; JAKOBSON, 1968).

A percepção categorial em uma nova língua chamada de audição fonológica, forma-se simultaneamente com o programa motor que responde não somente pela articulação de um som concreto. Ela 
também responde por quais órgãos discursivos participam na formação das diferentes características da LE e com qual intensidade, quais as combinações que funcionam no trabalho articulatório dos órgãos da fala e que são possíveis em tal LE (ZINDER, 1979, p. 81). Os psicólogos, neste caso, falam sobre os mecanismos de fonação ou os mecanismos de formação externa da comunicação. Durante o ensino/aprendizagem de uma LE, tais mecanismos funcionam de uma forma diferente da maneira como eles funcionam de acordo com os programas da LM, isto é, aqui tem lugar uma seqüência de comandos silábicos motores dos movimentos articulatórios (ZIMNIAIA, 1989).

O sistema de correspondências sonoras que surge durante a interferência, não permite ao indivíduo reproduzir corretamente as formas sonoras de uma determinada palavra durante a produção do discurso e tão pouco permite a percepção adequada da palavra, baseando-se apenas em suas características objetivas, de acordo com o sistema da LE em pauta. A explicação disto deve-se à passagem de transição dos sistemas fonéticos interagentes que, sem levar em consideração a sua labialização, a sua má estruturação, falando metaforicamente, forma uma espécie de composição "híbrida", que se identifica como inicial e assim, a partir do segundo sistema sonoro, possui as suas características sintagmáticas, paradigmáticas e diferenciais (LYUBIMOVA, 1991).

O discurso incorreto dos estrangeiros durante o processo de aprendizagem de uma determinada LE, pelo menos no que diz respeito ao seu aspecto fonético incorreto, é mais uma manifestação dessa variação dentro dos limites dos sistemas da LE, mas que ocorre em virtude da ação da interferência durante as condições da formação do bilingüismo. A variação fonética do discurso de estrangeiros pode extrapolar os limites das propriedades do sistema lingüístico de uma determinada LE (o subsistema), formando, dessa forma, o seu próprio sistema (outro subsistema). Mas o mesmo pode coincidir com algumas características de algum dialeto ou algum tipo de falares, o que abre caminho para um outro sistema, que pode não ter nada a ver com o primeiro sistema. Naturalmente que tal sistema pode variar, não 
somente no discurso de aprendizes de diferentes idiomas, mas também no discurso de portadores de um mesmo idioma. Dessa mesma maneira, pode variar também o número de indivíduos que utilizam esta ou aquela variante.

Nesse caso, podemos constatar que existe algo em comum, por exemplo, com aquilo que está presente a todos os russos que não dominam a língua portuguesa. Aqui, os sistemas lingüísticos individuais, obrigatoriamente, interagem, isto é, possuem alguma determinada parte em comum que nos permite falar a respeito do sotaque russo no discurso na língua Portuguesa. Mas os sistemas intermediários e os interagentes são os primeiros sistemas representados por diferentes línguas até mesmo se entre esses sistemas não existe nenhuma semelhança genética ou tipológica. Desta forma, sabemos bem que os falantes de diferentes idiomas podem cometer os mesmos erros fonéticos no discurso na língua russa. Um exemplo disso pode servir a violação das oposições das consoantes surdas e sonoras, duras e brandas, cometidas por indivíduos falantes de diferentes línguas.

As pesquisas necessárias para o trabalho da articulação e a realização desta ou daquela característica diferencial, em cada caso concreto, sem dúvida nenhuma, possui "as suas características". Isso porque refletem não somente o "conflito" sistêmico, mas também o "conflito" do trabalho mecânico de fonação, formado anteriormente, em relação ao que está se formando, em resultado das tentativas por parte do aprendiz, em produzir o discurso normativo fonético na LE em questão. Desta forma, temos aqui a violação das oposições fonêmicas e as violações das variações alofônicas. Assim, devemos observar que em uma determinada etapa do domínio de alguma LE, a composição fonêmica dos sistemas interagentes, em um grau significativo, coincide, porque supõe-se que, em condições de um bilingüismo subordinativo, o sistema intermediário baseia-se, antes de mais nada, nos componentes universais da linguagem, entre eles os sistemas fonéticos e demais sistemas. As diferenças entre esses sistemas, de acordo com as suas semelhanças tipológicas genéticas, devem ser expressas principalmente através do caráter variativo dos seus 
alofones e suas correspondências com os fonemas da LE que se estuda.

A descrição fonética da formação do discurso em uma LE, até hoje, limita-se à descrição de um determinado número de realizações fonêmicas. A identificação das funções fonológicas e dos sons, com a qual o indivíduo trabalha durante o domínio incompleto de uma LE, apresenta determinadas dificuldades, mencionadas inúmeras vezes na literatura que aborda tal assunto. Realmente, por um lado, nós conhecemos as unidades que os sons representam - que são os fonemas de uma determinada língua. Por outro lado, reconhecer isso ainda não nós é possível, pois a realização concreta de um determinado fonema contém um determinado som, que corresponde ou a um fonema do primeiro sistema, ou a um fonema de um outro sistema lingüístico, ou, finalmente, esse fonema não é característico nem do primeiro e nem do segundo sistema. Além disso, não podemos deixar de reconhecer que, normalmente, todas as análises realizadas nesse sentido evidenciam uma assimetria na realização das características fonêmicas durante a percepção ou a produção do discurso. Tais características demonstram, como já dissemos acima, o fato de que o indivíduo é capaz de distinguir uma grande quantidade de fonemas, apesar de não se encontrar em condições ativas de utilizá-los no discurso.

Neste caso, a questão pode relacionar-se a fonemas com múltiplos alofones, cuja unidade deve-se à identificação das palavras, nas quais eles podem apresentar-se em qualquer uma das variantes facultativas (ZINDER, 1979, p. 73). Tal tipo de unidade podemos chamar de diafonema (LYUBIMOVA, 2001), compreendendo que o conceito dessa unidade possui um caráter duplo, que se manifesta em relação ao sistema intermediário, onde ela se apresenta como uma unidade paradigmática. Entretanto, em relação ao sistema de uma determinada língua, ela pode apresentar-se com um caráter sintagmático, pois as suas variantes são a realização dos fonemas dessa língua. Lembramos que já falamos a respeito do caráter duplo sistêmico dessas unidades, durante o domínio incompleto do aspecto 
fonético do discurso na LE (HAUGEN, 1956; ROZENTSVEIG, 1972). Entretanto, este caráter duplo sistêmico normalmente é analisado como uma característica de ambos os sistemas lingüísticos em contato. Em relação aos aspectos paradigmáticos e sintagmáticos desta questão, salientamos que os mesmos ainda não foram analisados suficientemente, pois o termo "diafonema" até hoje não foi utilizado. Diante do exposto, o termo "diafone", de acordo com a teoria de Jones (1950) e de acordo com a teoria de E. Haugen (1954), não são idênticos ao conceito de "diafonema". Os componentes das variantes de um diafonema podem coincidir, em primeiro lugar, com os alofones de fonemas semelhantes do primeiro sistema; em segundo lugar, com os alofones de diferentes fonemas do segundo sistema. Mas devemos levar em consideração que são possíveis composições mais complexas: alofones de diferentes fonemas do segundo sistema e alofones de fonemas semelhantes do primeiro sistema; ou ainda uma composição múltipla, que inclui alofones desconhecidos, tanto no primeiro sistema quanto no segundo. Evidentemente, tais tipos de unidades são possíveis e pode haver uma coincidência total com os alofones de fonemas do segundo sistema.

A veracidade de tal conceituação pode ser demonstrada através dos resultados de um amplo círculo de pesquisas baseadas em materiais de diferentes línguas em contato, que consideram não somente o aspecto segmental, mas também o nível supra-segmental dos componentes fonológicos dos idiomas em questão.

\section{NOTAS}

${ }^{1}$ Nina A. Lyubimova - Doutora em Ciências Filológicas, áreas Lingüística Geral e Teoria e Metodologia do Ensino de Língua Estrangeira. Professora Titular da Faculdade de Filologia, Universidade Federal de São Petersburgo, São Petersburgo - Rússia.

${ }^{2}$ Tanira Castro - Professora Adjunto do Setor de Russo, Departamento de Línguas Modernas - LET2, Instituto de Letras - UFRGS. 


\section{REFERÊNCIAS BIBLIOGRÁFICAS}

BERNSHTEIN, S.I. ${ }^{1}$ Voprosy obutchenia proiznosheniu (primenitelno kprepodavaniu russkogo iazyka inostrantsam) // Voprosy fonetiki i obutchenie proiznosheniu. M.: MGU, 1975. Questões relativas ao ensino-aprendizagem da pronúncia (aplicadas ao ensino da lingua russa para estrangeiros). // Questões relativas à fonética e ao ensino-aprendizagem da pronúncia. Moscou: ed. da UFMoscou. 1975.

BONDARKO, L. V. Fonetitcheskoie opisanie iazyka i fonologitcheskoe opisanie retchi. L.: LGU, 1981. Descrição fonética da linguagem e descrição fonológica do discurso. Leningrado: Ed. LGU. 1981.

HAUGEN, E. Bilingualism in the Americas. A Bibliography and Guide to Research. Publications of the American Dialect Society University of Alabama 26, 1956.

HAUGEN, E. Problems of Bilingualism Description. Georgetown University Monograph Series on Language and Linguistics 7, September 1954, p. 9-19.

JONES, D. The Phoneme: Its Nature and Use. Cambridge, Heffner1950 (2 $2^{\text {nd }}$ ed. 1962; $3^{\text {rd }}$ ed. 1967).

JAKOBSON, R.O. Child Language, Aphasia and Phonological Universalis. The Hague; Paris: Mouton, 1968.

LYUBIMOVA, N.A. Fonetitcheskaia interpferentsya i obshenie na nerodnom iazyke (experimentalno-fonetitcheskoe issledovanie na materiale finsko-russkogo dvuiazytchia). SPb.: UFSPb, 1991. Ed. A interferência fonética e a comunicação na LE (pesquisa de fonética experimental baseada em material de bilingüismo russofinlandês). Resumo de tese de doutorado. São-Petersburgo: Ed. UFSPb, 1991.

LYUBIMOVA, N.A. On phonetic Language Interference and the Intermediate System. // 100 Years of Experimental Phonetics in Russia. S.- Petersburg: Ed. UFSPb, 2001. P. 127-130.

ROZENTSVEIG, V. I. Iazykovyie kontakty. Lingvistitcheskaia problematika. L.: Nauka, 1972. Contatos lingüísticos. Questões de lingüística. Leningrado: Ed. Nauka. 1972.

WEINREICH, U. Languages in Contact: findings and problems. Linguistic Circle of New York, New-York, 1953.

ZIMNIAIA, I.A. Psikbologia obutchenia nerodnomu iazyku. M.: Russki iasyk, 1989. Psicologia do ensino-aprendizagem de uma lingua estrangeira. Moscou: Ed. Russki Iasyk. 1989.

ZINDER, L.R. Obshchaia fonetika. M.: Vyshaia shkola, 1979. Fonética Geral. Moscou: Ed. Vyschaia Skola. 1979. 